\section{The Origins of the Institute}

Under the directorship of Professor Dr. Dieter Häussinger, the unit of infectious diseases, which forms part of the Department of Gastroenterology, Hepatology, and Infectious Diseases, was expanded with the addition of a tropical medicine outpatient clinic. With its fundamental research, clinical research projects, and an increasing number of patients the field of infectious diseases now forms another mainstay within the department besides gastroenterology and clinical and experimental hepatology. The department was also certified as a Center of Infectious Diseases several years ago.

This development is reflected architecturally in the opening of the Center for Liver and Infectious Diseases in 2011. This ultramodern building houses, among others, the only treatment unit in North Rhine-Westphalia for highly infectious patients e. g. those infected with Ebola.

A further ambitious and logical step was the establishment of a branch of the Department of Gastroenterology, Hepatology, and Infectious Diseases in a tropical country with the possibility of research into infectious diseases and tropical medicine in an area with a high prevalence of such diseases. Further aims were to set up an international partnership, a continuous bilateral transfer of knowledge and to support an African university in the areas of medical research, teaching, and the treatment of patients. In addition, it was to be made possible for internists to do their complete training in tropical medicine at the Department of Gastroenterology at the University of Düsseldorf under the directorship of Professor Dr. Häussinger.

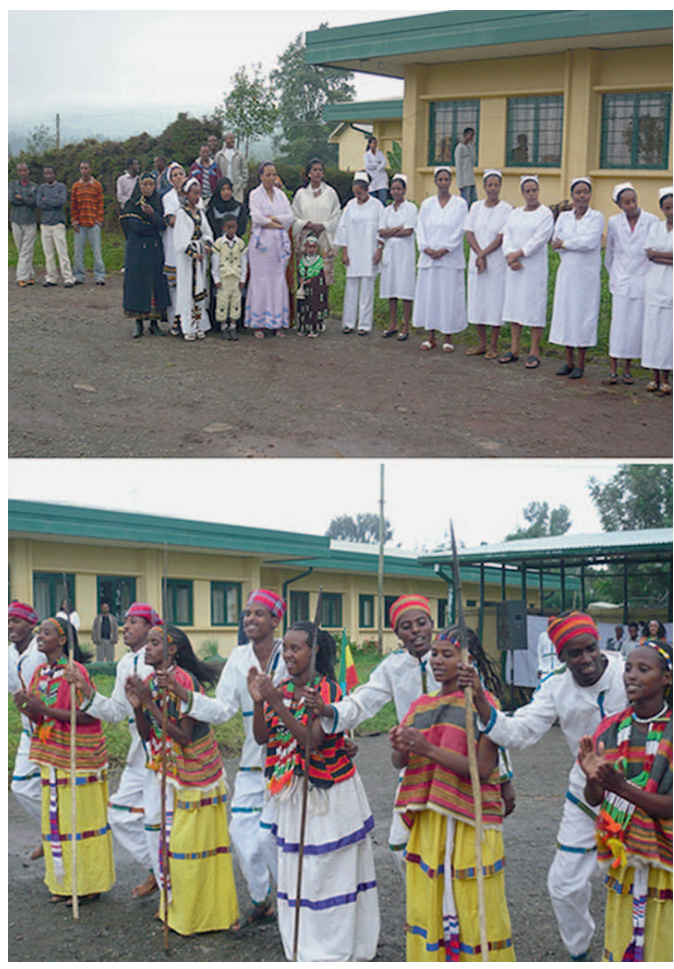

Reception with traditional dancing during Professor Häussinger's first visit to Asella Teaching Hospital in 2009

The University in Adama in Ethiopia offered a suitable location and a possible longer-term partnership between the two universities. After many years of political and military conflicts and various repressive regimes as well as periods of famine caused by droughts, Ethiopia is now enjoying a phase of political stability and continuous economic recovery. Even so, Ethiopia is still one of the poorest and least developed countries in the world. With approximately 500,000 inhabitants, Adama is one of the largest cities of the country. The capital Addis Ababa, the only major city in Ethiopia, lies $90 \mathrm{~km}$ to the northwest. 
In 2006, a teaching school became "Adama Science and Technology University” (ASTU). The aim of the Ethiopian government was to establish a German-style model university. A German university president (Professor Dr. H. Eichele) was appointed and most faculties were governed by renowned, experienced deans from Germany. In 2011/12, the model of the German-Ethiopian dual leadership ended as planned. In 2013, there were up to 20,000 students enrolled in the rapidly growing university.

The medical faculty of the university was founded in 2009. It was to be based in the small town of Asella, which nevertheless is the regional center of the Arsi zone. The city is situated $70 \mathrm{~km}$ south of Adama and is mainly characterized by agriculture. The Faculty of Agriculture was already located here.

The main hospital at Asella serves an area inhabited by 3.5 million people. Patients from three (nine are planned) district hospitals and a variety of health centers are referred there. The following specialties are offered: internal medicine, gynecology, pediatrics, and general surgery. Furthermore, a major HIV/AIDS clinic, an eye clinic, a dental clinic, and a project for the care of rectovaginal fistulas common in Ethiopia as well as radiology, laboratory, and microbiology departments are integrated into the hospital.

Affiliated to the hospital, a school for nursing, midwives, and laboratory assistants has also been in existence for many years.

The emergent medical faculty was established under the deanship of Professor Dr. Dietrich Birnbaum (former Medical Director and Executive Director of the Kerckhoff Hospital in Bad Nauheim) and he presided over it for sev-

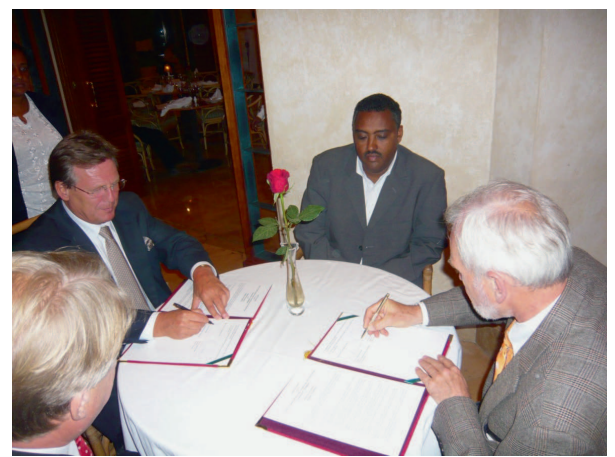

Signing of the letter of intent for future cooperation during a visit of Professor Häussinger to Ethiopia in September 2009. M. Biontino (German Deputy Ambassador), Professor Dr.D. Häussinger, His Excellency D. Mekonnen (then Ethiopian Minister of Education), and Professor Dr.H. Eichele (then President of the University of Adama) (l.t.r.)

eral years. Thus, this fledgling medical faculty seemed most suitable as a partner for the Düsseldorf project and contact was duly made and developed further. In September 2009, a "letter of intent" was signed by Professor Dr. Häussinger, Professor Dr. Eichele, and the then Ethiopian Minister of Education Ato Mekonnen.

The cooperation agreement between the Medical Faculty of Heinrich Heine University Düsseldorf, the University Hospital of Düsseldorf, and the ASTU was signed on June $21^{\text {st }} 2010$. After the institute was planned, built, and equipped, it was inaugurated on October $16^{\text {th }}$ 2013 by Professor Häussinger, Professor Lee (President of the ASTU), Professor Schnitzler (Prorector of Heinrich Heine University), and Dr. Legesse (Dean of the Medical Faculty of the ASTU). Since the inauguration, the Department of Gastroenterology, Hepatology, and Infectious Diseases at the University Hospital of Düsseldorf has almost continuously been represented in Ethiopia by two German physi- 


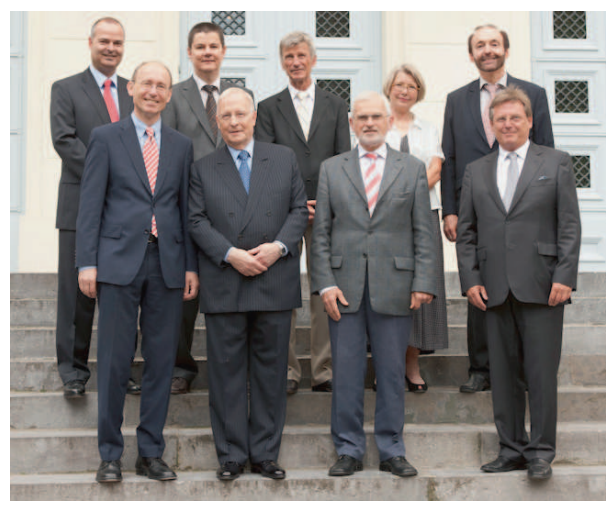

Signing of the agreement between representatives of Adama University (Ethiopia), of Heinrich Heine University (Düsseldorf) and the University Hospital of Düsseldorf at Schloss Mickeln in Düsseldorf on July $21^{\text {st }}$ 2010: front row, I.t.r.: Professor Dr. Dr. H. M. Piper (Rector of the HHU Düsseldorf), W. Hirsch (after whom the institute is named, benefactor, founder, and managing partner of the Hirsch Group), Professor Dr. H. Eichele (President of Adama University), Professor Dr. D. Häussinger (Director of the Department of Gastroenterology, Hepatology, and Infectious Diseases). Back row I.t.r.: Dr.M. Wokittel (Administrative Director of the University Hospital Düsseldorf), Professor Dr. J. Windolf (Dean of the Medical Faculty, HHU), Professor Dr. D. E. Birnbaum (Dean of the Medical Faculty, Adama University), Ms.C. Herrmann (Ministry of Innovation, Science, and Research), Professor Dr. Werner Stüber (Dean, School of Humanities and Natural Sciences, Adama University)

cians as coordinators of the HITM. The institute is mainly financed by funds raised by the founder and director, Professor Häussinger,

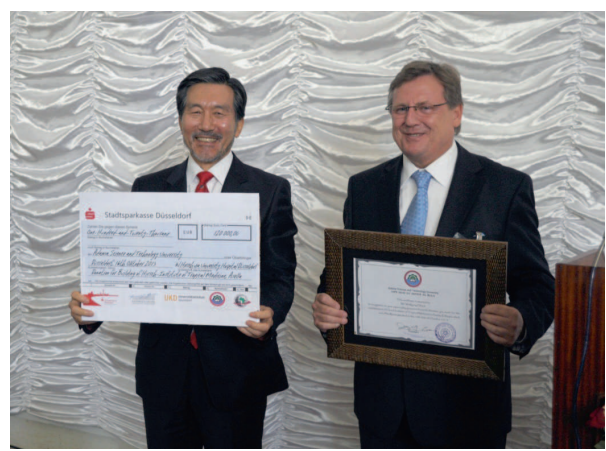

Official presentation of the check by Professor Häussinger to Professor Lee, President of Adama Science and Technology University, during the inauguration in October 2013 and furthermore, his continuous commitment guarantees stable financial and material support from German partners, foundations, and donors.

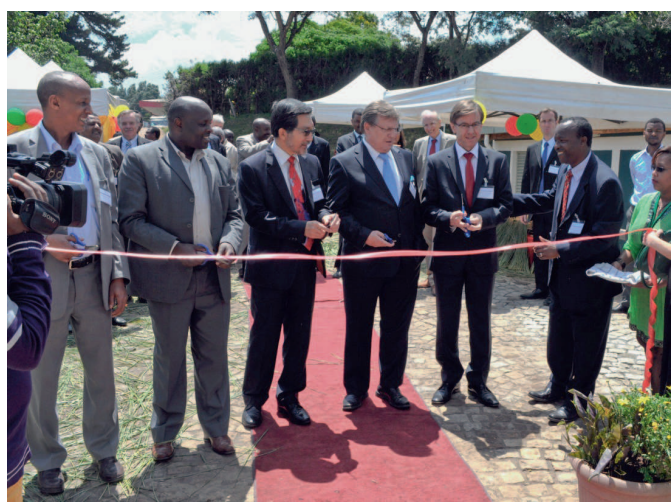

The inauguration on October $16^{\text {th }} 2013$

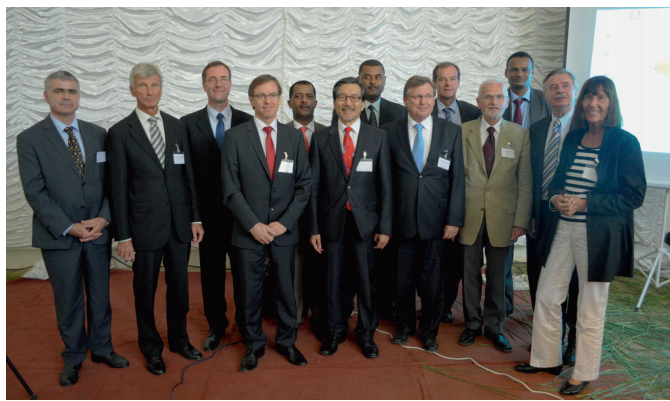

The delegations at the inauguration of the institute: (I.t.r.) Professor Gerald Heusing (DAAD), Professor Dietrich Birnbaum (Dean of the Medical Faculty of the ASTU), Dr. Torsten Feldt (Consultant and Assistant Director, HITM), Professor Alfons Schnitzler (Prorector, HHU), Dr. Lemi Guta (Vice President of Research, ASTU), Professor Jang Gyu Lee (President of the ASTU), Dr. Habtamu Kabur (Vice President of Administration, ASTU), Professor Dieter Häussinger (Director, HITM), Mr. Thomas Terstegen (Permanent Representative at the German Embassy in Addis Ababa), Professor Herbert Eichele (former President of the ASTU), Dr. Tolla Beriso (First Secretary for Education and Science of Oromia State), Professor Herbert Becker (DAAD), and Dr. Irmela Müller-Stöver (Tropical Medicine, University Hospital of Düsseldorf) 


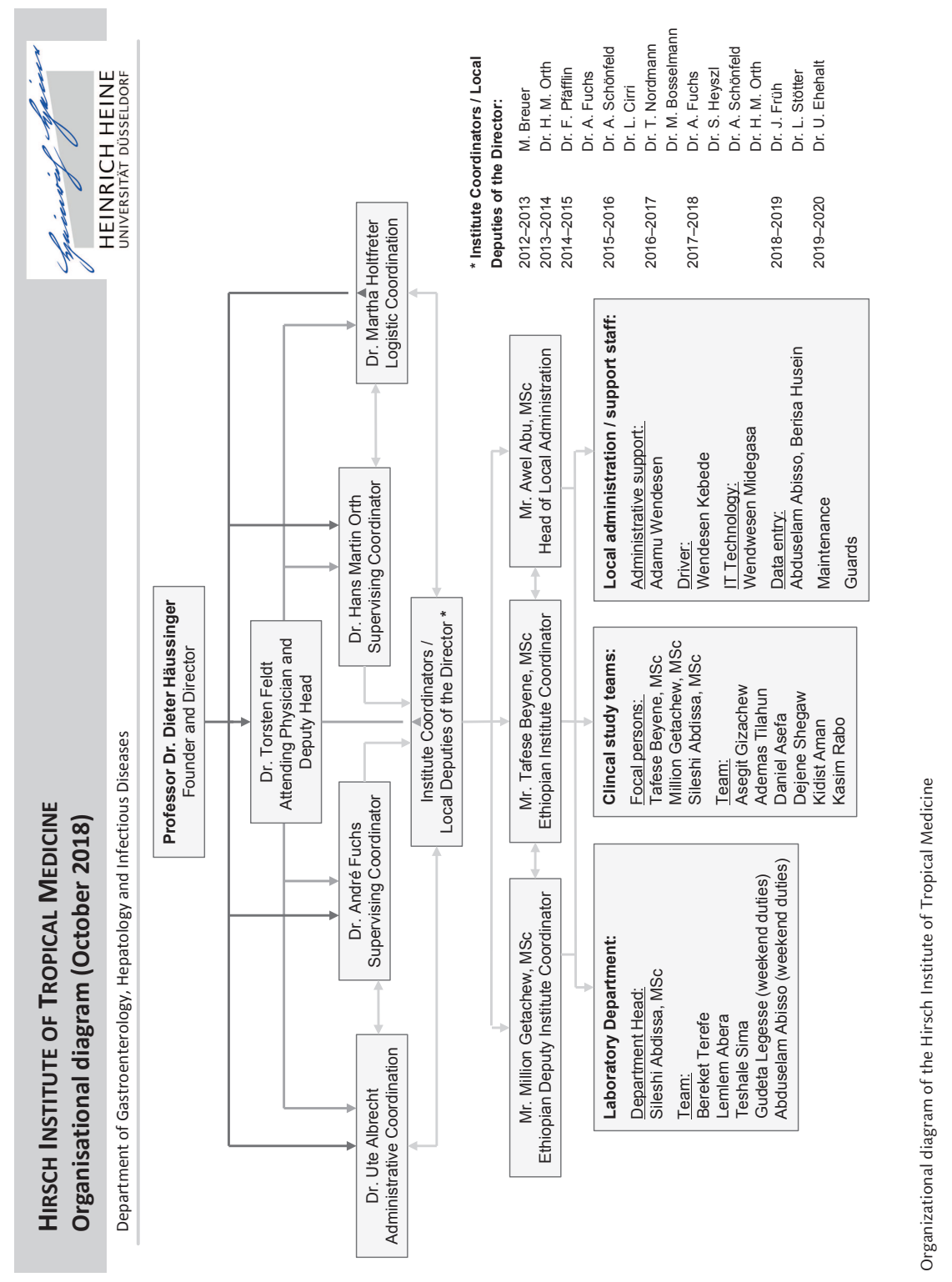




\section{Coffee Ceremony}

Coffee is not only one of the most important export goods of Ethiopia; coffee drinking is also deeply rooted in Ethiopian culture. On special occasions a coffee ceremony is performed, which, with all the steps included, may take over an hour. The guests to be entertained are seated on small stools in a semicircle around the woman that gracefully performs the coffee ceremony. The floor of the area where the ceremony takes place is decorated with fresh grass. A fire is lit. The performer of the ceremony uses a piece of ember to light some incense, which spreads a fragrant smell inside the room. Traditionally, chickpeas or wheat are roasted and later offered as snacks with the coffee.

Then the hostess cleans and roasts the green coffee beans in a pan on the fire. The powerful aroma of the coffee promises imminent pleasure. While the roasted beans are crushed into coarse grounds in a wooden mortar, the water is heated in a clay coffeepot. The freshly roasted and ground coffee is added to the boiling water. After a few minutes, the coffee is ready and served in small bowl-shaped cups. The first cup is dedicated to "Mother Earth" and not drunk. The experienced hostess manages to fill the cups in a single stream. Plenty of sugar is added to the traditionally prepared, very strong coffee, before it is drunk. Guests at the elaborate ceremony indulge in lively conversation. The coffee ceremony is performed, when the German employees of the institute in Asella are invited to visit the families of their Ethiopian colleagues or, in an especially lavish way, when the assignment of a German employee in Asella has ended. The impressive ceremony serves a double purpose, enjoying the coffee and communicating socially: in Ethiopia, everybody is allowed to speak openly on any topic. 


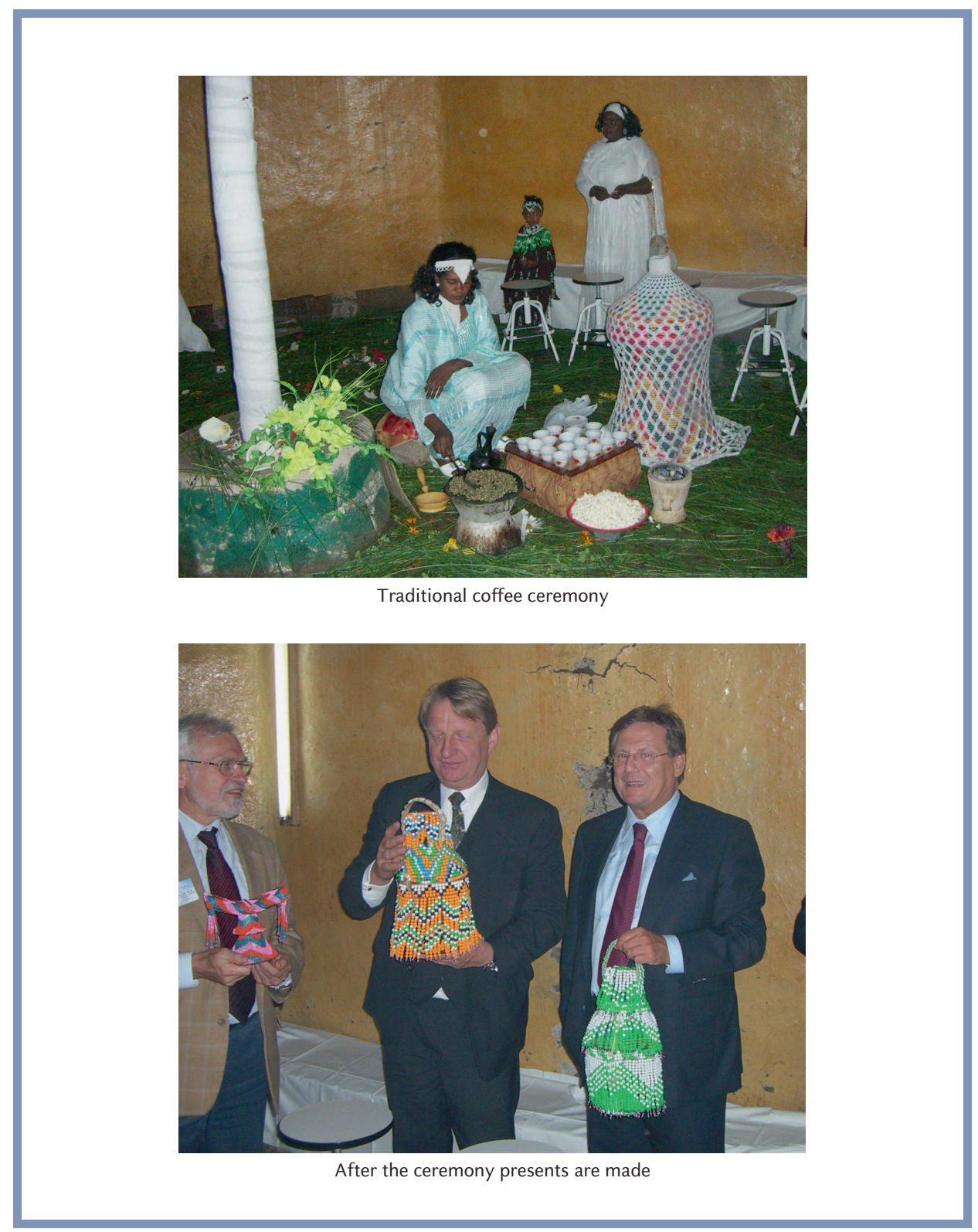

